\title{
$\beta$-carotene adsorption onto mesoporous carbon-coated monolith column: dynamic studies
}

\begin{abstract}
$\beta$-carotene adsorption dynamics from isopropyl alcohol (IPA) solution onto a mesoporous carbon-coated monolith (MCCM) column was studied. Kinetics and mass transfer parameters were modeled. Thomas and Adams-Bohart models were applied to the experimental data obtained from dynamic studies. The effects of bed depth, flow rate, and influent concentration on breakthrough curves and adsorption capacity were investigated. The results showed that $\beta$-carotene equilibrium uptake increased with decreasing flow rate and increasing influent concentration. The optimum adsorption capacity $(1.37 \mathrm{mg} / \mathrm{g})$ was achieved at 20 $\mathrm{mg} / \mathrm{L}$ initial $\beta$-carotene concentration, $47.5 \mathrm{~cm}$ bed height, and $1.0 \mathrm{~mL} / \mathrm{min}$ flow rate. The time to attain breakthrough point decreased, while a sharp breakthrough curve was observed with increase in flow rate and influent concentration and a decrease in bed height.
\end{abstract}

Keyword: Adsorption dynamics; $\beta$-carotene; Isopropyl alcohol; Mesoporous carbon-coated monolith 